\title{
The second case of Horn Kolb Syndrome in the same woman in Turkey, diagnosed prenatally at 16 weeks of pregnancy
}

\author{
Kahraman Ülker, ${ }^{1}$ Yetkin Karasu, ${ }^{1}$ Murat Bozkurt, ${ }^{1}$ Servet Gençdal, ${ }^{1}$ Duygu Kara \\ Bozkurt, ${ }^{2}$ Levent Şahin ${ }^{1}$
}

Keywords: Acheiropodia, acheiria, transverse limb defect, Horn Kolb syndrome

\begin{abstract}
Background

Acheiropodia is a rare form of skeletal dysplasias. It is characterized by the amputation of the upper and lower extremities and with aplasia of the hands and feet. Acheiropodia formerly was known as a disease affecting only people of Brazilian ancestry. The first case out of Brazil was reported from our clinic in 2012. In the present report, we summarize the second case of acheiropodia, which was diagnosed prenatally in the same patient.
\end{abstract}

Case

A 39 years old G7P2A4 pregnant woman admitted to our clinic for a regular obstetrics visit at 16th weeks gestation in May 2013. Her history was significant for early pregnancy oligohydramnios with fetal loss. In the postabortion examination, the fetus was found to be affected with acheiropodia. Since she had a history of acheiropodia a detailed ultrasound examination was performed. The fetal head and body including the intra-cranial, thoracic and abdominal structures were normal; however, distal long bones of the upper and the lower extremities could not be demonstrated. Three days later she was admitted with vaginal bleeding. Post abortion macroscopic examination revealed the absence of distal parts of the both upper and lower extremities without any other demonstrable anomalies.

\section{Conclusion}

Acheiropodia is a rare disease which may be seen outside of South America. Evaluation of the continuity and normal appearance of the extremities should be integrated to the routine antenatal ultrasound examination.

${ }^{1}$ Department of Obstetrics and Gynecology, Kafkas University School of Medicine, Kars, Turkey

${ }^{2}$ Department of Radiology, Kafkas University School of Medicine, Kars, Turkey

\section{Introduction}

Acheiropodia (Horn Kolb Syndrome) is characterized with the amputation of the upper and lower extremities and with the

Please cite this paper as: Ülker K, Karasu Y, Bozkurt M, Gençdal S, Kara Bozkurt D, Şahin L. The second case of Horn Kolb Syndrome in the same woman in Turkey, diagnosed prenatally at 16 weeks of pregnancy. Proceedings in Obstetrics and Gynecology, 2015;5(1):Article1 [ 6 p.]. Available from: http://ir.uiowa.edu/pog/. Free full text article.

Corresponding author: Murat Bozkurt, Assistant Professor, Kafkas Üniversity Kampüsü Sağlık Araştırma ve Uygulama Hastanesi. Bülbül Mahallesi. Kombine Yolu Üzeri 3600 Kars/TURKEY. Tel: 905322279072, 905056330044. Fax: 047422514 30. E-Mail: jindrmb@yahoo.com

Financial Disclosure: The authors report no conflict of interest.

Received: 29 December 2014; received in revised form: 2 March 2015; accepted 4 March 2014; POG in Press, 25 March 2015

Copyright: (c) 2015 Ülker et al. This is an open-access article distributed under the terms of the Creative Commons Attribution License, which permits unrestricted use, distribution, and reproduction in any medium, provided the original author and source are credited. 
aplasia of the hands and feet. It affects only the extremities without other systemic manifestations. ${ }^{1}$ Prior to 2010 , acheiropodia had only been reported in Brazilians with Portuguese ancestry. In 2010 the first case of acheiropodia outside the Brazil was diagnosed in our clinic and published in 2012. ${ }^{2}$ The affected gene locus on the chromosome $7 q 36$ could not be demonstrated in that case. ${ }^{3}$ In this case report we present the second case of Horn Kolb Syndrome from Turkey.

\section{Case Report}

A multiparous G7P2A4 woman who had previously aborted a fetus, which was the first case of Horn Kolb Syndrome in Turkey, was admitted to our clinic for her scheduled prenatal visit at 16 weeks gestation in May 2013. Her 5th gestation, complicated with acheiropodia, had been terminated due to the severe oligohydramnios followed by fetal demise in 2010. Her sixth pregnancy resulted in the birth of a healthy girl in 2012.

The present pregnancy had been confirmed at 7th gestational week and she had had antenatal visits and ultrasound exams at the 7th and 12th weeks, both without remarkable findings. Ultrasound at the first prenatal visit and first trimester screening were also normal. She was taking folic acid supplementation (400 microgram/day). Physical examination of the woman was unremarkable and there was no history of any known teratogenic exposure in the pre or post-conception period.

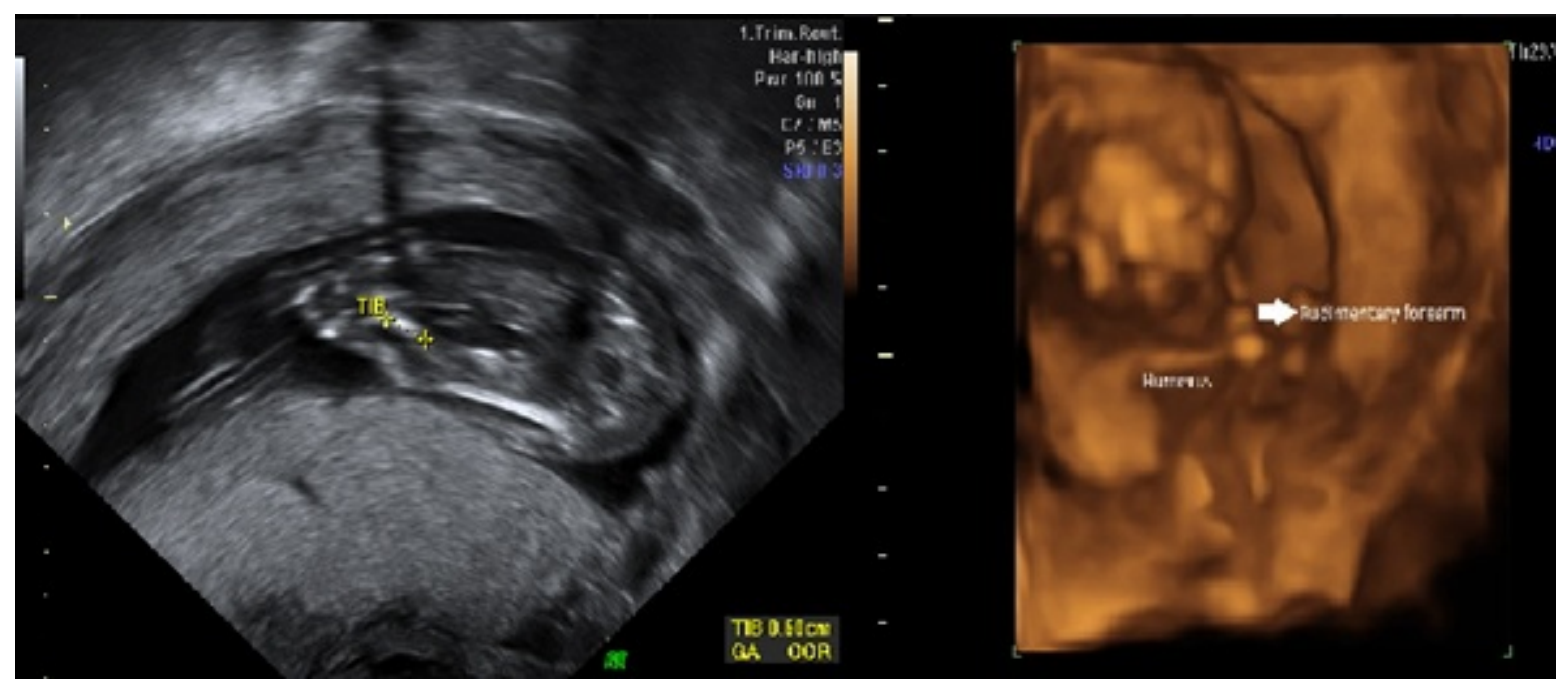

Figure 1: 2D and 3D ultrasound images revealed the only tiny ossification foci at the places where the radiuses, ulnas, tibias, feet and hands must exist

Since the woman had aborted a fetus complicated with acheiropodia previously, a detailed ultrasound examination was performed and a fetus compatible with 16 weeks was seen in the ultrasound. A detailed examination of fetal head and body including the intra cranial, thoracic and abdominal 
structures was unremarkable. The long bones of the proximal parts of the extremities, femur and humerus, were demonstrated with their appropriate lengths and shapes. However, the distal long bones of the upper and lower extremities could not be demonstrated. There were only tiny ossification foci at the places where the radiuses, ulnas, tibias, feet and hands must exist (Figure 1).
Although we did not have the facilities to demonstrate the locus on chromosome 7q36, we planned an amniocentesis procedure for fetal karyotyping and a magnetic resonance imaging examination at 17th gestational week. However, three days after this visit the woman admitted once again with vaginal bleeding and abdominal pain. She was hospitalized and aborted the fetus approximately three and a half hours later.

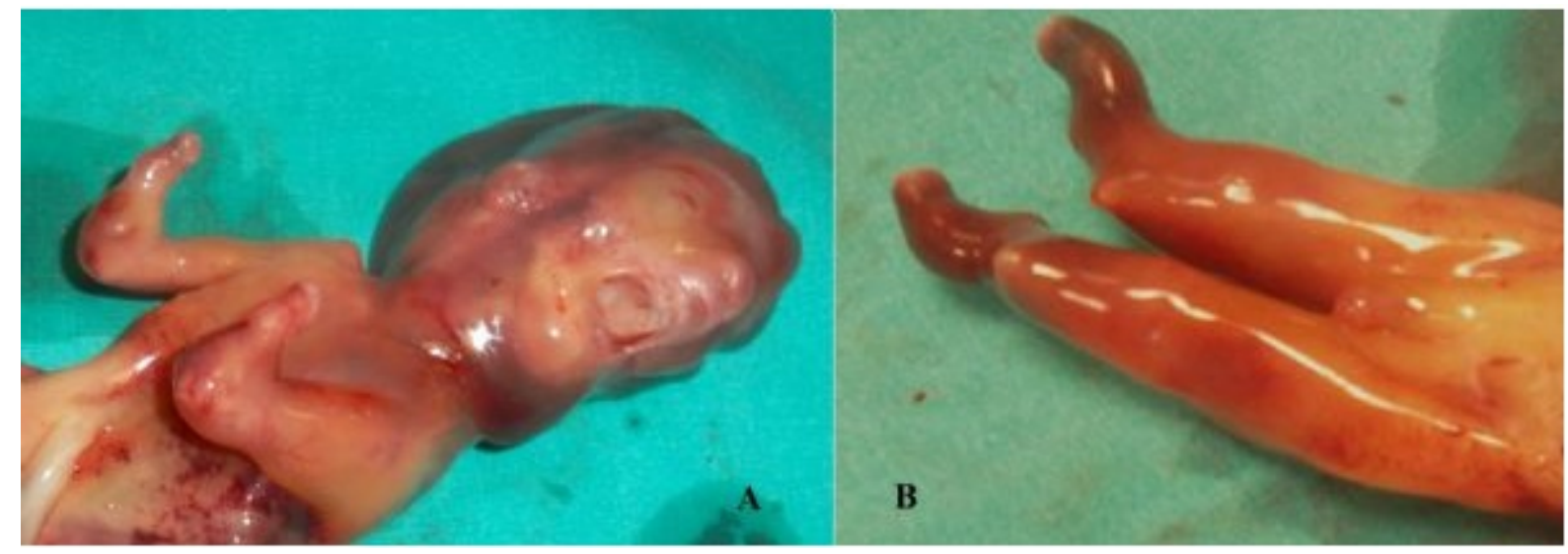

Figure 2: Post abortion macroscopic examination revealed the absence of distal parts of the both upper and lower extremities without any other demonstrable anomalies

Post abortion macroscopic examination confirmed the diagnosis of acheiropodia. Distal parts of the upper and lower extremities were not present (Figure 2). Post abortion X-ray examination confirmed the distal extremity dysplasia (Figure 3). There was no other demonstrable abnormality.

\section{Discussion}

Acheiropodia is a rare form of skeletal dysplasia that previously has been seen in Latin America, particularly in Brazil, with all cases reported from related families living in rural areas. ${ }^{4-6}$ In 2012, the first case of acheiropodia was reported in Turkey. ${ }^{2}$ This case was the 5th pregnancy of a multiparous woman, which was complicated with anhydramnios and intrauterine fetal demise. The present case was the 7th pregnancy of the same woman. She had delivered a healthy girl baby in her sixth gestation.

Acheiropodia (Horn Kolb Syndrome) is a rare form of skeletal dysplasias, which is characterized with bilateral congenital amputation of all extremities. ${ }^{7}$ Skeletal dysplasias are a large, heterogeneous group of disorders affecting the 
formation and growth of bones. The overall birth prevalence of skeletal dysplasias is estimated to be 2.4 per
10,000 births. $^{8}$ The estimated incidence of acheiropodia in Brazil is approximately $1 / 250,000$ in all births.

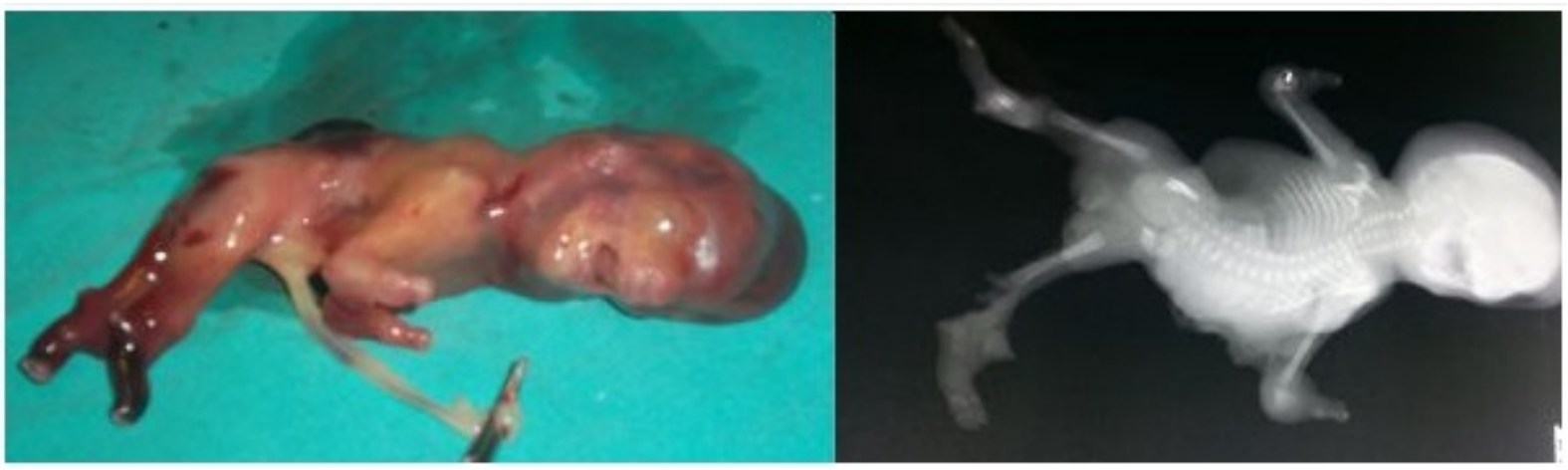

Figure 3: Post abortion X- ray examination confirmed the distal extremity dysplasia

The low incidence of the disease makes its antenatal diagnosis difficult. Although the American College of Obstetrics and Gynecology (ACOG) recommends evaluation of all extremities as a part of standard examination, ${ }^{9}$ the fetal femur is usually only measured and the long bone evaluated during the second trimester ultrasound. Parilla et al. reported that accurate prenatal diagnosis of skeletal dysplasia are difficult. In their series of 31 cases only 20 patients were correctly diagnosed in the antenatal period $^{10}$ In another serious of 38 patients, Witters et. al. reported that accurate antenatal diagnosis of the type of the skeletal dysplasia was $65.8 \%{ }^{11}$ Both of the studies concluded that ultrasound is a very reliable way to determine the lethality of the diseases. ${ }^{10,11}$

lanakiev et. al. summarized pedigrees of five known families. It was noticed that in none of the families, were there intrauterine fetal demise or spontaneous abortions. ${ }^{12}$ However in our patient there were 3 spontaneous first trimester losses, two term healthy deliveries (one is still alive, other one was lost due to pneumonia at 8th month of life) and two affected pregnancies ending with spontaneous intrauterine fetal death. We don't know whether the previous early losses were also affected or not.

Acheiropodia is an autosomal recessive disease. The heterozygote carriers are phenotypically normal. ${ }^{12}$ A locus for acheiropodia was mapped on chromosome $7 q 36 .^{3}$ For the present case we could not demonstrate the mutation during the antenatal period and then postnatal chromosome analysis was not accepted by the family because of the economic difficulties. To our knowledge this is the first case of Horn Kolb Syndrome diagnosed antenatally.

At this point the ethical dilemma is that, acheiropodia is not lethal and not associated with any other systemic malformation as far as known. Voluntary termination of pregnancy is allowed until 
10th gestational week in Turkey. Sharony et al. concluded that skeletal dysplasia could be diagnosed as early as the 14th week of gestation by ultrasound. $^{13}$ Thus, early accurate differential diagnosis of acheiropodia from other skeletal dysplasias is a compelling situation. Since managing a disease, which is severely disabling but not lethal, is very difficult both for the physicians and the families.

\section{Conclusion}

Acheiropodia is a rare disease that may be seen outside the South America. Though it is not always helpful for the final accurate diagnosis of acheiropodia, evaluation of the continuity and normal appearance of the extremities should be integrated to the routine antenatal ultrasound examination.

\section{References}

1. Freire-Maia A, Freire-Maia N, Schull WJ. Genetics of acheiropodia (the handless and footless families of Brazil). IX. Genetic counseling. Hum Hered. 1975;25(4):329-36.

http://dx.doi.org/10.1159/000152743.

PubMed PMID: 126945.

2. Temur I, Ulker K, Volkan I, Karaca $M$, Ersoz M, Gul A, Adiguzel E. The first case of Horn Kolb Syndrome in Turkey, diagnosed prenatally at the 23(rd) week of a pregnancy: A very rare and unusual case far from the original geography. Am J Case Rep. 2012;13:106-8. doi: 10.12659/AJCR.883025. Epub 2012 Jun 13. PubMed PMID: 23569502; PubMed Central PMCID: PMC3615972.
3. Escamilla MA, DeMille MC, Benavides E, Roche E, Almasy L, Pittman S, Hauser J, Lew DF, Freimer NB, Whittle MR. A minimalist approach to gene mapping: locating the gene for acheiropodia, by homozygosity analysis. Am J Hum Genet. 2000 Jun;66(6):19952000. http://dx.doi.org/10.1086/302921. Epub 2000 Apr 25. PubMed PMID: 10780921; PubMed Central PMCID: PMC1378047.

4. Silveira EL, Freire-Maia A. Acheiropodia: new cases from Brazil. Clin Genet. 1998 Sep;54(3):256-7. http://dx.doi.org/10.1111/j.13990004.1998.tb04299.x. PubMed PMID: 9788736.

5. Fett-Conte AC, Richieri-Costa A. Acheiropodia: report on four new Brazilian patients. Am J Med Genet. $1990 \quad$ Jul;36(3):341-4. http://dx.doi.org/10.1002/ajmg.13203603 20. PubMed PMID: 2363435.

6. Freire-Maia A, Li WH, Maruyama $\mathrm{T}$. Genetics of acheiropodia (the handless and footless families of Brazil). VII. Population dynamics. Am J Hum Genet. 1975 Sep;27(5):665-75 http://dx.doi.org/10.1111/j.1469-

1809.1975.tb00118.x. PubMed PMID: 1163539; PubMed Central PMCID: PMC1762833.

7. Toledo SP, Saldanha PH. A radiological and genetic investigation of acheiropody in a kindred including six cases. J Genet Hum. 1969 May;17(1):81-94. PubMed PMID: 5808544.

8. Camera G, Mastroiacovo P. Birth prevalence of skeletal dysplasias in the Italian Multicentric Monitoring System for Birth Defects. Prog Clin Biol Res. 1982;104:441-9. PubMed PMID: 7163285. 
9. American College of Obstetricians and Gynecologists. ACOG Practice Bulletin No. 101: Ultrasonography in pregnancy. Obstet Gynecol. 2009 Feb;113(2 Pt 1):451-61. doi: 10.1097/AOG.0b013e31819930b0.

PubMed PMID: 19155920.

10. Parilla BV, Leeth EA, Kambich MP, Chilis $\mathrm{P}$, MacGregor SN. Antenatal detection of skeletal dysplasias. J Ultrasound Med. 2003 Mar;22(3):255-8; quiz 259-61. PubMed PMID: 12636325.

11. Witters I, Moerman P, Fryns JP. Skeletal dysplasias: 38 prenatal cases. Genet Couns. 2008;19(3):267-75. PubMed PMID: 18990981.

12. Ianakiev $P$, van Baren $M J$, Daly $M J$, Toledo SP, Cavalcanti MG, Neto JC, Silveira EL, Freire-Maia A, Heutink $P$, Kilpatrick MW, Tsipouras P. Acheiropodia is caused by a genomic deletion in C7orf2, the human orthologue of the Lmbr1 gene. Am J Hum Genet. 2001 Jan;68(1):38-45. Epub $2000 \quad$ Nov 22. http://dx.doi.org/10.1086/316955.

PubMed PMID: 11090342; PubMed Central PMCID: PMC1234933.

13. Sharony R, Browne C, Lachman RS, Rimoin DL. Prenatal diagnosis of the skeletal dysplasias. Am J Obstet Gynecol. 1993 Sep;169(3):668-75. http://dx.doi.org/10.1016/00029378(93)90641-U. PubMed PMID: 8372878. 